\title{
A mathematical Model to assess the Role of Neglected Control Techniques in the Dynamics of Banana Xanthomonas Wilt Disease
}

\author{
John Joel Mapinda ${ }^{1,2}$, Gasper Godson Mwanga ${ }^{3}$, Nkuba Nyerere ${ }^{4}$, and Verdiana Grace Masanja ${ }^{1}$ \\ ${ }^{1}$ Department of Applied Mathematics, The Nelson Mandela African Institution of Science and Technology, \\ P.O. Box 447, Arusha, Tanzania
}

${ }^{2}$ Department of Mathematics and IT, Mwalimu Julius K. Nyerere University of Agriculture and Technology, P.O. Box 976, Musoma, Tanzania

${ }^{3}$ Department of Physics, Mathematics and Informatics, University of Dar es Salaam, P.O. Box 2329, Dar es Salaam, Tanzania,

${ }^{4}$ Department of Mathematics and Statistics, Sokoine University of Agriculture, P.O. Box 3000, Morogoro, Tanzania

\begin{abstract}
Banana Xanthomonas Wilt disease (BXW) is a destructive bacterial disease that highly threatens banana production in East and Central Africa. It is caused by a bacteria known as. In this paper, a mathematical model for the dynamics and control of BXW disease is formulated and analyzed. Numerical simulations were performed to examine the impact of participatory community education programmes, clearance of Xcm bacteria in the soil, single diseased stem removal, and vertical transmission control strategies. It was found that participatory community farming education programmes, timely removal of infected banana plants, clearance of Xcm bacteria in the soil dramatically reduce the number of secondary infections hence greatly contributing to the control of the BXW disease. The study recommends that, along with the existing control measures such as sterilization of farming tools, timely removal of the male bud using a forked stick and planting healthy suckers, more emphasis should be invested in educating farmers on disease detection and management strategies and increasing the rate of clearing Xcm bacteria in the soil so as to avoid persistence of the disease in the farms.
\end{abstract}

Keywords: Control Measures; Banana Xanthomonas Wilt Disease; BXW; Contaminated Soil; Mathematical Model.

\section{INTRODUCTION}

Food security is one of the major problems facing developing countries. Food crops such as cassava, banana, maize, rice and potatoes are grown in east and central Africa to overcome the problem of food security. According to Food and Agriculture Organization (FAO) statistics (2017), Banana is One of the most significant food crops in East and central Africa. It comes after cassava, maize, and sweet potatoes. Farmers use banana fruits to serve different purposes, such as food and for commercial purposes to support their livelihoods. Commercially, bananas are used to create fiber, banana wine, banana beer, and as ornamental plants to a lesser extent. Africa contributes up to $17.6 \%$ of all banana grown in the world (see Figure 1)[1]. Tanzania, Rwanda, Kenya, Cameroon, Angola, and Egypt are the primary producers of bananas in Africa. Despite these achievements, banana farming in east and central Africa is endangered by deteriorating soil fertility, diseases and pest [2]. 


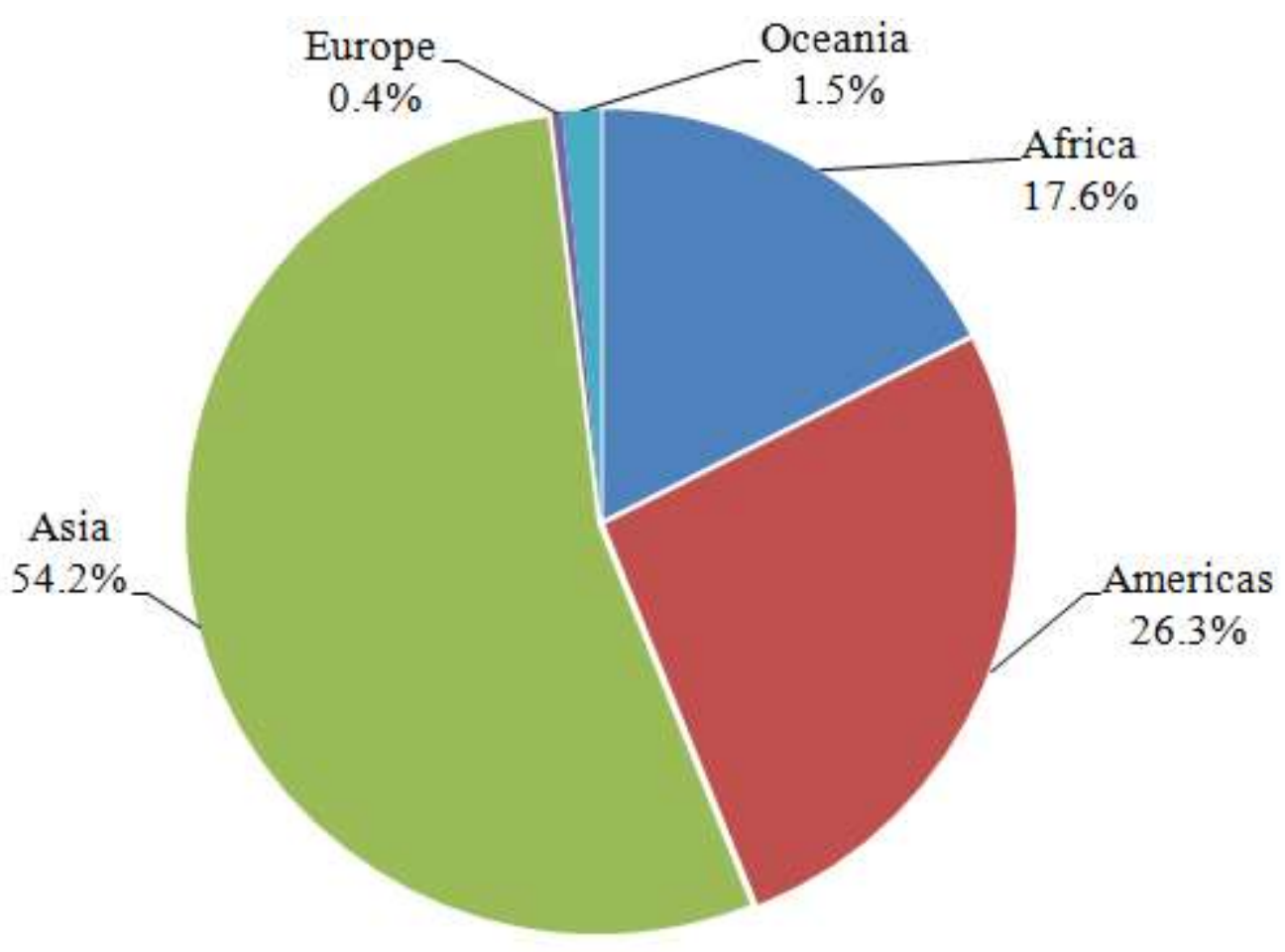

Figure 1: Banana production shares by region for the year 2017

Diseases affecting banana plants includes: Banana Xanthomonas Wilt (BXW); Banana weevils; Nematodes; and Sigatoka leaf spots. Banana Xanthomonas Wilt (BXW) has been reported to be the major disease which threatens banana farming in East Africa, which in turn affects the livelihood of the farmers and other people who depend on banana for their living [3]. BXW is a highly destructive disease caused by a bacterium called Xanthomonas campestris pv.musac-earum (Xcm) [4]. BXW if not timely controlled, can affect the whole farm and the whole banana plants in the region.

Insect vectors, contaminated farming implements, contaminated soil, infected planting suckers, and the transportation of latently infected plants are predominant means that the Xcm bacterium is spread from infected banana plants to Susceptible plants. Birds, bats, and other flying insects like bees are vectors that spread the $\mathrm{Xcm}$ bacteria from a diseased banana plant to a vulnerable banana plant. Birds and Bats play a significant role in long distant transmission of Xcm [5]. Birds and Bats transmit Xcm bacteria to the male buds of a vulnerable banana plant after eating the ripe banana fruits or upon feeding of nectar of an infected banana plant [5]. Other vectors such as bees transmit the disease to a susceptible banana plant when contaminated with Xcm bacteria from a male bud of an infected plant, feeding on unsafe disposed remove banana plants and rarely from an inoculated farming tool [6]. Through farming activities like weeding, pruning, removing access suckers, harvesting, and male bud removal, a susceptible plant might be infected by a contaminated farming implements [7]. Physical injuries induced by farming activities such as weeding and digging in the farm, a susceptible banana plant can acquire Xcm bacteria from the contaminated soil [8]-[11]. Xcm bacteria can also be vertically transmitted from the diseased mother plant to the lateral shoots [12].

The common signs of Banana Xanthomonas Wilt disease (BXW) are Yellowing and withering of leaves; premature ripening and rotting of the banana fruits; blackening and shriveling of male bud flower; and yellow ooze detected on the cross section cut of the banana plant pseudo stem; and eventually death of the entire plant [13], [14]. Figure 2 subplot (a), (b) and (c) shows the yellowing and withering of leaves, yellow ooze detected on the cross section cut of the pseudo stem and rotting of the banana fruits respectively. 


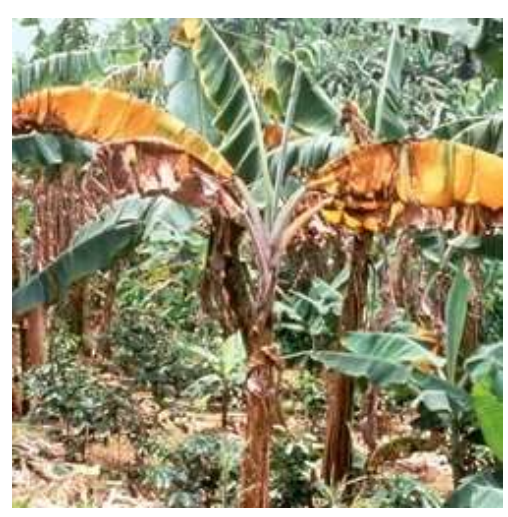

(a) Yellowing of banana leaves

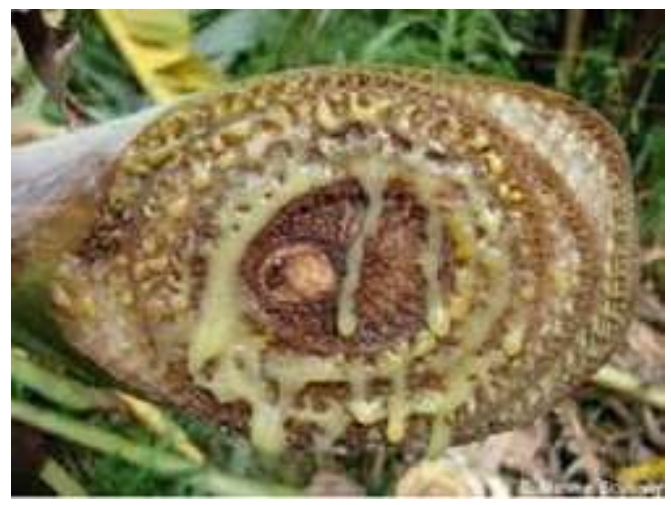

(b) Yellow ooze on the cross section cut of the pseudo stem

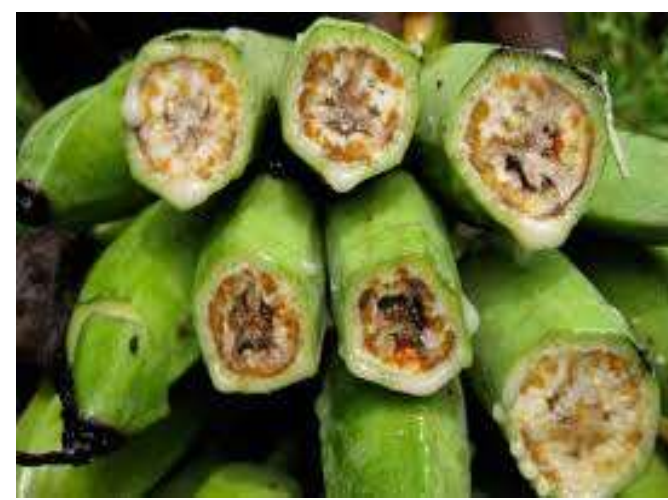

(c) Rotting of banana fruits

Figure 2: Symptoms of the BXW Disease.

According to Maina et al [15], timely removal of the male bud by a forked stick effectively control the spread of the BXW disease by insect vectors. Also Buregyeya [16] studied the long distance spread of BXW disease, in his study Buregyeya observed that $\mathrm{Xcm}$ bacteria can stay in the room temperature on cutting tools for up to 22 days. Therefore, the study revealed that disinfection of farming tools and avoid to use cutting tools for pruning in an infected field are reasonable ways to eliminate mechanical transmission of BXW disease. Kubiriba et al [17] observed that the use of education campaigns to raise farmers awareness on different control measures if essential for BXW disease management. Scholars, Ocimati et al [18] and Blomme et al [19] observed that it is possible to remove the diseased plant and leave the health plant to grow. Ntamwira et al [20] also observed that timely removal of an infected banana plant for the mat is more effective compared to removing the whole mat which is time consuming, expensive and requires more labour. Moreover, Uwamahoro et al [21] studied the BXW disease control strategies in Rwanda. Uwamahoro revealed that community education programs helps farmers to get the right BXW disease information and hence helps in controlling the disease.

Mathematical models play a critical role in understanding the transmission patterns of BXW disease, providing the best combination of control strategies to limit the disease's catastrophic impacts. Mathematical models also help in planning, implementing and evaluating the disease detection, control and prevention measures [22], [23]. In order to understand the dynamics of BXW disease, several scholars have developed mathematical models to study the transmission dynamics of BXW and its controls. Horub et al [24] developed a mathematical model to study the transmission dynamics of BXW disease by vectors and its controls. The study showed that timely removing the male bud using a forked stick, increasing rougeing and planting health suckers helps to reduce transmission of the disease. Nannyonga et al [25] developed a mathematical model to assess the impact of using contaminated tools in the recurrence of BXW disease. The study revealed that sterilization of farming tools has a great impact in reducing BXW disease recurrence. Nakakawa et al [3] formulated a mathematical model to examine the role of roguing and debudding in controlling the BXW disease. The study showed that the number of infected banana plants decreases faster when de-budding, roguing and sterilization of farming tools are regularly applied. Again, Nakakawa et al [26] developed a mathematical model to study the transmission dynamics of BXW disease by considering the vertical and vector modes of transmission. The study pointed out that, single stem removal of the diseased plant is the reasonable strategy to control inflorescence infection. Under the assumption that there of no tool based transmission, the study further indicated that controlling inflorescence infection and roguing regularly eliminate the BXW disease on the farm. Furthermore, Kweyunga et al [27] developed a mathematical model to study the transmission dynamics of BXW disease. The study considered both horizontal and vertical modes of transmission and included forces of infection from both asymptomatic and symptomatic infected banana plants. It was observed that parameters from asymptomatic infected banana plants are more sensitive to the basic reproduction number. Moreover, Mapinda et al [28] modified the model by Kweyunga et al [27] to include contaminated soil. The results showed that soil inoculum plays an important role in the persistence of the disease in the farm setting.

However, despite the number of mathematical models developed there is little information on the impact of participatory community education programmes, clearance of $\mathrm{Xcm}$ bacteria in the soil, single diseased stem removal and control of vertical transmission in limiting the disease spread. Therefore, this study aims at developing a deterministic mathematical model to assess the impact of participatory community education programmes, clearance of $\mathrm{Xcm}$ bacteria in the soil, single diseased stem removal and control of vertical transmission as control strategies in eliminating BXW disease. 


\section{MATERIAL AND METHODS}

\subsection{Model Formulation}

In this paper, a mathematical model for the transmission dynamics of BXW by [28] is modified to include some control measures. The model involves the banana population and insect vector population. The banana plant population is subdivided into three compartments: susceptible banana plant $\left(S_{p}\right)$; asymptomatic infectious banana plants $\left(I_{a}\right)$; and symptomatic infected banana plants $\left(I_{S}\right)$. Susceptible banana plants are thought to have an equal probability of becoming infected when coming into touch with the $\mathrm{Xcm}$ bacteria. Susceptible banana plants acquire BXW disease through vertical transmission, contaminated farming tools, soil contaminated with Xcm bacteria, planting of asymptomatic infected suckers or insect vector [5], [9], [12].

We assume that vectors are contaminated with $\mathrm{Xcm}$ bacteria from both symptomatic and asymptomatic infected banana plants. In this model, the vector population is subdivided into a susceptible vector $\left(S_{v}\right)$ and vectors contaminated with Xcm bacteria $\left(I_{v}\right)$. Therefore, banana plant total population is given by $N_{p}=S_{p}+I_{a}+I_{s}$ and total vector population is $N_{v}=S_{v}+I_{v}$. An environment contaminated with Xcm bacteria is represented by $A_{h}$.

The model considers constant recruitment of banana plants by emerging new healthy lateral shoots (suckers) from the banana plants and replanting at the rate of $b_{p}$. It is assumed that the banana plant can be vertically infected from a diseased mother plant to the susceptible lateral shoots from a symptomatic and asymptomatic infected banana plant at the rate of $\theta$ and $\delta$ respectively [12]. A farming tool can be contaminated with $\mathrm{Xcm}$ bacteria from symptomatic infected banana plants or asymptomatic infected banana plants and transmit the disease at the rate $\beta_{s}$ or $\beta_{a}$ respectively. Also, susceptible banana plants can be infected by the $\mathrm{Xcm}$ bacteria found in the soil at a rate of $\omega_{2}$. The average daily contact rate of an infected vector to a susceptible banana plant is given by $a$, and $\omega_{1}$ is the probability that the contact results in infection. Matured banana plants are harvested at the rate of $\alpha_{p}$. Asymptomatic infected banana plant progress to symptomatic infected banana plant at the rate of $q$ after showing BXW symptoms. An infected banana plant can be removed from the farm at the rate of $r$ or die due to infection at a rate of $d$.

The susceptible vector population has a constant recruitment rate of $b_{v}$, and it is assumed that both susceptible and contaminated vectors die naturally at the rate of $\mu_{v}$. The parameter $\omega_{3}$ caters for the probability that a susceptible vector gets contaminated with $\mathrm{Xcm}$ bacteria after coming into contact with an infected banana plant. It is also assumed that the vector becomes infectious right after being contaminated with the Xcm bacteria. According to [5] , contaminated vectors retain Xcm bacteria viable for 3-5 days from the day of inoculation. This implies that after 5 days contaminated vectors become susceptible again at the rate $\eta$. Furthermore, it is assumed that $\eta<\mu_{v}$. Xcm bacteria released by dead banana plants due to infection removed BXW diseased plant and other infected banana plant debris when not safely disposed and left in the farm result to Xcm soil inoculum at the rate of $\phi$ [11]. The Xcm bacteria in the farm soil are cleared naturally at the rate $\mu_{h}$ due to lack of saprophytic or resting stage in soil $[8]$.

The control parameters included in the basic model includes participatory community education programmes $(\xi)$; clearance of $\mathrm{Xcm}$ bacteria in the soil $(\psi)$; vertical transmission control $(\delta)$; and Single diseased stem removal $(r)$ whose values range from 0 to 1. For instance, $\xi$ is an education parameter that ranges from 0 to 1 , where 1 represents effective community participation in farming education programmes which ensure no new BXW disease transmission and 0 represent poor community participation in farming education programmes which lead to a lack of disease information to the farmers and hence high BXW disease transmission. $(1-\delta)$ is a control parameter to control vertical infection from the mother plant to its suckers. $\psi$ is an artificial clearance rate of $\mathrm{Xcm}$ bacteria in the soil and $r$ represent timely identification and removal of the diseased plant only and not the whole mat. Figure 3 is a schematic diagram that best describes the model for the dynamics of BXW disease with control measure. 


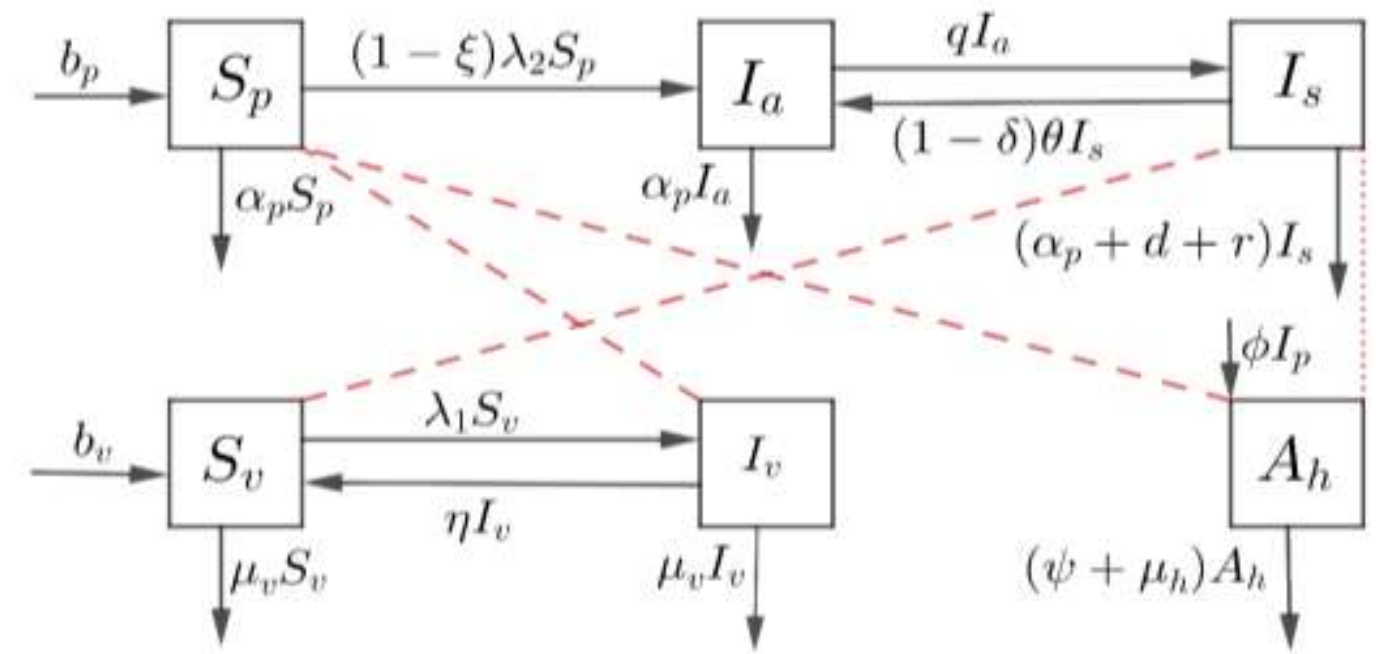

Figure 3: Compartmental diagram for the dynamics of BXW disease with control.

In the compartmental diagram, solid lines represent a transition from one infection stage to another; recruitment, harvesting, natural death rate of vectors and clearance of $\mathrm{Xcm}$ bacteria from the soil. The dashed lines represent interactions between infectious and susceptible compartments while shedding of $\mathrm{Xcm}$ bacteria into the environment is represented by dotted lines. From the compartmental diagram we formulate a system of differential equations as follows:

$\frac{d S_{p}}{d t}=b_{p}-(1-\xi)\left(a \omega_{1} \frac{S_{p} I_{v}}{N_{p}}+\beta_{a} \frac{S_{p} I_{a}}{N_{p}}+\beta_{s} \frac{S_{p} I_{s}}{N_{p}}+\omega_{2} \frac{S_{p} A_{h}}{N_{p}\left(K+A_{h}\right)}\right)-\alpha_{p} S_{p}$,

$\frac{d I_{a}}{d t}=(1-\xi)\left(a \omega_{1} \frac{S_{p} I_{v}}{N_{p}}+\beta_{a} \frac{S_{p} I_{a}}{N_{p}}+\beta_{s} \frac{S_{p} I_{s}}{N_{p}}+\omega_{2} \frac{S_{p} A_{h}}{N_{p}\left(K+A_{h}\right)}\right)+(1-\delta) \theta I_{s}-\alpha_{p} I_{a}-q I_{a}$,

$\frac{d I_{s}}{d t}=q I_{a}-\alpha_{p} I_{s}-d I_{s}-r I_{s}$

$\frac{d A_{h}}{d t}=\phi I_{s}-\mu_{h} A_{h}-\psi A_{h}$

$\frac{d S_{v}}{d t}=b_{v}+\eta I_{v}-a \omega_{3} \frac{S_{v} I_{S}}{N_{p}}-\mu_{v} S_{v}$

$\frac{d I_{v}}{d t}=a \omega_{3} \frac{S_{v} I_{S}}{N_{p}}-\eta I_{v}-\mu_{v} I_{v}$.

From the model equations (1-6), banana plants total population and vectors total population are given by equation (7) and

$\frac{d N_{p}}{d t}=b_{p}-\alpha_{p} N_{p}+(1-\delta) \theta I_{s}-(d+r) I_{s}$,

$\frac{d N_{v}}{d t}=b_{v}-\mu_{v} N_{v}$

Table 1: Model variables description

\begin{tabular}{cl}
\hline Variable & Description \\
\hline$S_{p}$ & Susceptible banana plants \\
$I_{a}$ & Asymptomatic infected banana plants
\end{tabular}


International Journal of Advances in Scientific Research and Engineering (ijasre), Vol 8 (1), January -2022

\begin{tabular}{cl}
\hline Variable & Description \\
\hline$I_{S}$ & Symptomatic infected banana plants \\
$S_{v}$ & Susceptible vector \\
$I_{v}$ & Vectors contaminated with Xcm bacteria \\
$A_{h}$ & Concetration of Xcm bacteria in the soil \\
\hline
\end{tabular}

Table 2: Description of the model Parameters

\begin{tabular}{cl}
\hline Parameters & Description \\
\hline$b_{p}$ & Recruitment rate of susceptible suckers \\
$b_{v}$ & Recruitment rate of susceptible vectors \\
$\alpha_{p}$ & Harvesting rate of Matured banana plants \\
$\theta$ & Rate of vertical transmission from an infected plant \\
$r$ & Rate of removing infected banana plant from the farm \\
$d$ & Disease induced death rate of an infected banana plant \\
$\beta_{a}$ & Rate of infection by contaminated farming tools from an asymptomatic infected banana plants \\
$\beta_{s}$ & Rate of infection by contaminated farming tools from symptomatic infected banana plants \\
$a$ & Contact rate of the vector with banana plant \\
$\omega_{1}$ & Probability that a contact results in transmission of Xcm bacteria from an \\
$\omega_{2}$ & infected vector to a susceptible banana plant \\
$\omega_{3}$ & Probability of transmission of Xcm bacteria from contaminated soil \\
$\mu_{b}$ & Probability that a contact results in the transmission of Xcm bacteria from \\
$\mu_{v}$ & an infected banana plant to a susceptible vector \\
$\eta$ & Mortality rate of the vectors \\
$q$ & Recovery rate of contaminated vectors \\
& Rate of an asymptomatic infected banana plant progress to symptomatic infected state
\end{tabular}

\section{MODEL ANALYSIS}

\subsection{Feasibility of the model solution}

In this section we are going to check whether the model system is epidemiologically and mathematically well posed. This is done by checking the invariant region of the model and positivity of the model solution to make sure that there is no negative solution to the model variables. From equation (7) we have

$$
\begin{aligned}
\frac{d N_{p}}{d t} & \leq b_{p}-\alpha_{p} N_{p} \\
N_{p}(t) & \leq \frac{b_{p}}{\alpha_{p}}+\left(N_{p}(0)-\frac{b_{p}}{\alpha_{p}}\right) e^{-\alpha_{p} t} .
\end{aligned}
$$


From equation (10), two cases are emerged. Case 1 : When $N_{p}(0) \leq \frac{b_{p}}{\alpha_{p}}$, as $t \rightarrow \infty$ the total number of banana plants $N_{p}(t)$ increases to $\frac{b_{p}}{\alpha_{p}}$. This implies that

$$
N_{p}(0) \leq N_{p}(t) \leq \frac{b_{p}}{\alpha_{p}}, \forall t \geq 0
$$

Case 2: When $N_{p}(0) \geq \frac{b_{p}}{\alpha_{p}}, N_{p}(t)$ decreases to $\frac{b_{p}}{\alpha_{p}}$ as $t \rightarrow \infty$. This implies that

$$
N_{p}(t) \leq \frac{b_{p}}{\alpha_{p}} \leq N_{p}(0), \forall t \geq 0
$$

Generally,

$$
D_{1}=\left\{S_{p}(t), I_{a}(t), I_{s}(t) \in \mathbb{R}_{+}^{3}: N_{p}(0) \leq N_{p}(t) \leq \frac{b_{p}}{\alpha_{p}}, \forall t \geq 0\right\}
$$

Again, from equation (8) we have

$$
\frac{d N_{v}}{d t} \leq b_{v}-\mu_{v} N_{v}
$$

solving

this,

results

into

$$
N_{v}(t) \leq \frac{b_{v}}{\mu_{p}}+\left(N_{v}(0)-\frac{b_{v}}{\mu_{v}}\right) e^{-\mu_{v} t}
$$

From equation (11) it follows that, When $N_{v}(0) \geq \frac{b_{v}}{\mu_{v}}$, as $t \rightarrow \infty$, The total number of vectors $N_{v}(t)$ reduces to $\frac{b_{v}}{\mu_{v}}$. This means that

$$
N_{v}(t) \leq \frac{b_{v}}{\mu_{v}} \leq N_{v}(0), \forall t \geq 0
$$

Again, when $N_{p}(0) \leq \frac{b_{p}}{\alpha_{p}}$, as $t \rightarrow \infty$ the number of vectors $N_{p}(t)$ approaches to $\frac{b_{v}}{\mu_{v}}$. This means that

$$
N_{v}(0) \leq N_{v}(t) \leq \frac{b_{v}}{\mu_{v}}, \forall t \geq 0
$$

Therefore,

$$
D_{2}=\left\{S_{v}(t), I_{v}(t) \in \mathbb{R}_{+}^{2}: N_{v}(0) \leq N_{v}(t) \leq \frac{b_{v}}{\mu_{v}}, \forall t \geq 0\right\}
$$

Furthermore, it is proved that

$$
D_{3}=\left\{A_{h}(t) \in \mathbb{R}_{+}^{1}, \forall t \geq 0\right\} .
$$

Considering the non-negative initial solutions of the model $S_{p}(0)>0, I_{a}(0) \geq 0, I_{s}(0) \geq 0, A_{h}(0) \geq 0, S_{v}(0) \geq$ $0, I_{v}(0) \geq 0$, the model system (1-6) is positive invariant and attracting in the region:

$$
D=\left\{D_{1} \times D_{2} \times D_{3}: D \in \mathbb{R}_{+}^{6} \forall t \geq 0\right\} .
$$

Therefore, the model solutions remain positive and bounded in the region $\mathrm{D}, \forall t \geq 0$. 
International Journal of Advances in Scientific Research and Engineering (ijasre), Vol 8 (1), January -2022

\subsection{Disease free equilibrium points}

Disease free equilibrium (DFE) is the point at which there is no infection in the population. Thus, the populations comprise of susceptible banana plants and susceptible vectors only. In order to determine the DFE points $X_{0}=\left(S_{p}^{0}, I_{a}^{0}, I_{s}^{0}, S_{v}^{0}, I_{v}^{0}, A_{h}^{0}\right)$ from the system (1-6) we set the rate of change of each model variable to zero. Thus,

$0=b_{p}-(1-\xi)\left(a \omega_{1} \frac{S_{p} I_{v}}{N_{p}}-\beta_{a} \frac{S_{p} I_{a}}{N_{p}}-\beta_{s} \frac{S_{p} I_{s}}{N_{p}}-\omega_{2} \frac{s_{p} A_{h}}{N_{p}\left(K+A_{h}\right)}\right)-\alpha_{p} S_{p}$

$0=(1-\xi)\left(a \omega_{1} \frac{s_{p} I_{v}}{N_{p}}+\beta_{a} \frac{S_{p} I_{a}}{N_{p}}+\beta_{s} \frac{S_{p} I_{s}}{N_{p}}+\omega_{2} \frac{s_{p} A_{h}}{N_{p}\left(K+A_{h}\right)}\right)+(1-\delta) \theta I_{s}-\alpha_{p} I_{a}-q I_{a}$

$0=q I_{a}-\alpha_{p} I_{s}-d I_{s}-r I_{s}$

$0=\phi I_{s}-\mu_{h} A_{h}-\psi A_{h}$

$0=b_{v}+\eta I_{v}-a \omega_{3} \frac{S_{v} I_{S}}{N_{p}}-\mu_{v} S_{v}$

$0=a \omega_{3} \frac{S_{v} I_{s}}{N_{p}}-\eta I_{v}-\mu_{v} I_{v}$

now, from equation (14) we have,

$$
I_{a}^{0}=\frac{\left(\alpha_{p}+d+r\right) I_{s}}{q}
$$

considering equation (15)

$$
A_{h}^{0}=\frac{\phi I_{s}}{\left(\mu_{h}+\psi\right)}
$$

Again solving equation (16) for $I_{v}^{0}$ results to

$$
I_{v}^{0}=\frac{a \omega_{3} S_{v} I_{s} I_{s}}{\left(\eta+\mu_{v}\right) N_{p}}
$$

Substituting the value of $I_{a}^{0}, A_{h}^{0}$, and $I_{v}^{0}$ in the equation (13), results to $0=\left(\frac{(1-\xi) a \omega_{1} S_{p} a \omega_{3} S_{v}}{\left(\eta+\mu_{v}\right) N_{p} N_{p}}+(1-\xi) \beta_{a} \frac{S_{p}}{N_{p}}+(1-\xi) \beta_{s} \frac{s_{p}\left(\alpha_{p}+d+r\right)}{q N_{p}}+\frac{(1-\xi) S_{p} \omega_{2} \phi}{N_{p}\left(K\left(\mu_{h}+\psi\right)+\phi I_{s}\right)}-\left(\alpha_{p}+q\right) \frac{\left(\alpha_{p}+d+r\right)}{q}+(1-\delta) \theta\right) I_{s}$ (17)

which shows that either

$$
I_{S}^{0}=0
$$

or

$$
M=0
$$

where 
$\mathrm{M}=\frac{(1-\xi) a \omega_{1} S_{p} a \omega_{3} S_{v}}{\left(\eta+\mu_{v}\right) N_{p} N_{p}}+(1-\xi) \beta_{a} \frac{s_{p}}{N_{p}}+(1-\xi) \beta_{s} \frac{s_{p}\left(\alpha_{p}+d+r\right)}{q N_{p}}+\frac{(1-\xi) S_{p} \omega_{2} \phi}{N_{p}\left(K\left(\mu_{h}+\psi\right)+\phi I_{s}\right)}-\left(\alpha_{p}+q\right) \frac{\left(\alpha_{p}+d+r\right)}{q}+(1-\delta) \theta$

substituting the value of $I_{s}^{0}$ into $I_{a}^{0}, A_{h}^{0}$, and $I_{v}^{0}$ results to

$$
I_{a}^{0}=A_{h}^{0}=I_{v}^{0}=0
$$

Again, Substituting equation $I_{s}^{0}, I_{a}^{0}, A_{h}^{0}$, and $I_{v}^{0}$ into equation (12) yields

$$
S_{p}^{0}=\frac{b_{p}}{\alpha_{p}} .
$$

Finally, Substituting equation $I_{s}^{0}, I_{a}^{0}, A_{h}^{0}$, and $I_{v}^{0}$ into equation (15) yields

$$
S_{v}^{0}=\frac{b_{v}}{\mu_{v}} .
$$

Therefore, the disease free equilibrium point $X_{0}$ of the system of equations (1-6) is given by

$$
X_{0}=\left(S_{p}^{0}, I_{a}^{0}, I_{s}^{0}, S_{v}^{0}, I_{v}^{0}, A_{h}^{0}\right)=\left(\frac{b_{p}}{\alpha_{p}}, 0,0, \frac{b_{v}}{\mu_{v}}, 0,0\right)
$$

\subsection{Effective reproduction number $\left(R_{e}\right)$}

Effective reproduction number $\left(R_{e}\right)$, is used to assess the effect of control measures. If $\left(R_{e}<1\right)$ it implies that the adoption of the control measures is effective and if $\left(R_{e}>1\right)$ then the adoption of the control measures is ineffective. $R_{e}$ helps to understand the ability of the disease to spread over the whole population when control measures are applied. This study applied the next generation method to compute the effective reproduction number $\left(R_{e}\right)$ as described by [29] and [30] and applied by [26]. From the model system of equations (1-6), consider the infected subsystem

$\frac{d I_{a}}{d t}=(1-\xi)\left(a \omega_{1} \frac{S_{p} I_{v}}{N_{p}}+\beta_{a} \frac{S_{p} I_{a}}{N_{p}}+\beta_{s} \frac{S_{p} I_{s}}{N_{p}}+\omega_{2} \frac{S_{p} A_{h}}{N_{p}\left(K+A_{h}\right)}\right)+(1-\delta) \theta I_{s}-\alpha_{p} I_{a}-q I_{a}$,

$\frac{d I_{s}}{d t}=q I_{a}-\alpha_{p} I_{s}-d I_{s}-r I_{s}$

$\frac{d A_{h}}{d t}=\phi I_{s}-\mu_{h} A_{h}-\psi A_{h}$

$\frac{d I_{v}}{d t}=a \omega_{3} \frac{S_{v} I_{s}}{N_{p}}-\eta I_{v}-\mu_{v} I_{v}$

Let $x_{1}=\left(I_{a}, I_{v}, I_{S}, A_{h}\right)$ and $y_{1}=\left(S_{p}, S_{v}\right)$, where $x_{1}$ and $y_{1}$ are infected and susceptible compartments of the model respectively. Separating the infected subsystem (19) - (22) into two parts, $\mathcal{F}(x, y)$ is the transmission part which portrays the production of new infections and $\mathcal{V}(\mathrm{x}, \mathrm{y})$ is the transition part which involves change of states:

$$
\mathcal{F}(x, y)=\left(\begin{array}{c}
(1-\xi)\left(a \omega_{1} \frac{S_{p} I_{v}}{N_{p}}+\beta_{a} \frac{S_{p} I_{a}}{N_{p}}+\beta_{s} \frac{S_{p} I_{s}}{N_{p}}+\omega_{2} \frac{S_{p} A_{h}}{N_{p}\left(K+A_{h}\right)}\right)+(1-\delta) \theta I_{s} \\
a \omega_{3} \frac{S_{v} I_{s}}{N_{p}} \\
0 \\
0
\end{array}\right),
$$


International Journal of Advances in Scientific Research and Engineering (ijasre), Vol 8 (1), January -2022

$$
\mathcal{V}(x, y)=\left(\begin{array}{c}
-\alpha_{p} I_{a}-q I_{a} \\
-\eta I_{s}-\mu_{v} I_{v} \\
q I_{a}-\alpha_{p} I_{s}-d I_{s}-r I_{s} \\
\phi I_{s}-\mu_{h} A_{h}-\psi A_{h}
\end{array}\right) .
$$

Let $F=\frac{\partial \mathcal{F}(x, y)}{\partial x_{i}}$ and $V=\frac{\partial \mathcal{V}(x, y)}{\partial x_{i}}$ where $x_{i}=\left(I_{a}, I_{v}, I_{s}, A_{h}\right)$ for $i=1,2,3,4$. At the DFE every member of the population is susceptible to the disease, thus $S_{p}^{0}=N_{p}(0)$. Differentiating and evaluating at $X_{0}$ results into $F$ and $V$

$$
\begin{aligned}
& F=\left(\begin{array}{cccc}
(1-\xi) \beta_{a} & (1-\xi) a \omega_{1} & (1-\xi) \beta_{s}+(1-\delta) \theta & (1-\xi) \frac{\omega_{2}}{K} \\
0 & 0 & \frac{a \omega_{3} \alpha_{p} b_{v}}{\mu_{v} b_{p}} & 0 \\
0 & 0 & 0 & 0 \\
0 & 0 & 0 & 0
\end{array}\right) \text {, } \\
& V=\left(\begin{array}{cccc}
\left(\alpha_{p}+q\right) & 0 & 0 & 0 \\
0 & \left(\eta+\mu_{v}\right) & 0 & 0 \\
-q & 0 & \left(\alpha_{p}+d+r\right) & 0 \\
0 & 0 & -\phi & \left(\mu_{h}+\psi\right)
\end{array}\right) \text {, } \\
& V^{-1}=\left(\begin{array}{cccc}
\frac{1}{\left(\alpha_{p}+q\right)} & 0 & 0 & 0 \\
0 & \frac{1}{\left(\eta+\mu_{v}\right)} & 0 & 0 \\
\frac{q}{\left(\alpha_{p}+q\right)\left(\alpha_{p}+d+r\right)} & 0 & \frac{1}{\left(\alpha_{p}+d+r\right)} & 0 \\
\frac{q \phi}{\left(\alpha_{p}+q\right)\left(\alpha_{p}+d+r\right)\left(\mu_{h}+\psi\right)} & 0 & \frac{\phi}{\left(\alpha_{p}+d+r\right)\left(\mu_{h}+\psi\right)} & \frac{1}{\mu_{h}+\psi}
\end{array}\right) .
\end{aligned}
$$

Multiplying $F$ and $V^{-1}$ results to $F V^{-1}$

$$
F V^{-1}=\left(\begin{array}{cccc}
T_{R} & \frac{(1-\xi) a \omega_{1}}{\left(\eta+\mu_{v}\right)} & T_{c} & \frac{(1-\xi) \omega_{2}}{k\left(\mu_{h}+\psi\right)} \\
\frac{a \omega_{3} \alpha_{p} b_{v} q}{\mu_{v} b_{p}\left(\alpha_{p}+q\right)\left(\alpha_{p}+d+r\right)} & 0 & \frac{a \omega_{3} \alpha_{p} b_{v}}{\mu_{v} b_{p}\left(\alpha_{p}+d+r\right)} & 0 \\
0 & 0 & 0 & 0 \\
0 & 0 & 0 & 0
\end{array}\right)
$$

Now, denote the matrix $Q=F V^{-1}$, the effective reproduction number $R_{e}$ of the model (1-6) is a largest eigenvalue of the matrix

$\mathrm{Q}$.

Therefore,

$$
R_{e}=\frac{1}{2} T_{R}+\frac{1}{2} \sqrt{\left(T_{R}\right)^{2}+4 \frac{(1-\xi) a^{2} \omega_{1} \omega_{3} \alpha b_{v} q}{\left(\eta+\mu_{v}\right) \mu_{v} b_{p}(\alpha+q)(\alpha+d+r)}} .
$$

Where, 
International Journal of Advances in Scientific Research and Engineering (ijasre), Vol 8 (1), January -2022

$$
T_{R}=\frac{(1-\xi) \beta_{e}}{\alpha_{p}+q}+\frac{\left((1-\xi) \beta_{i}+(1-\delta) \theta\right) q}{\left(\alpha_{p}+q\right)\left(\alpha_{p}+d+r\right)}+\frac{(1-\xi) \omega_{2} \phi q}{k\left(\alpha_{p}+d+r\right)\left(\alpha_{p}+q\right)\left(\mu_{h}+\psi\right)},
$$

and

$$
T_{C}=\frac{(1-\xi) \beta_{i}+(1-\delta) \theta}{\alpha_{p}+d+r}+\frac{(1-\xi) \omega_{2} \phi}{k\left(\alpha_{p}+d+r\right)\left(\mu_{h}+\psi\right)} .
$$

From the effective reproduction number $\left(R_{e}\right)$, shows that increasing farmers participatory in farming education programmes $(\xi)$ decreases the average number of new infections $\left(R_{e}\right)$. Clearing of Xcm bacteria in the soil $(\psi)$ reduces the life span of Xcm bacteria in the soil and hence reduces the ability of the disease to transmit through the soil. Timely removal of diseased plants $(r)$ reduces the average time at which an infected banana plant stays in a symptomatic infected stage which reduces the further spread of the BXW disease in the field. Furthermore, an increase in the control to avoid vertical transmission $(\delta)$ reduces the further spread of the BXW disease from the mother plant to its suckers and hence reduces the effective reproduction number.

\section{NUMERICAL SIMULATIONS}

In the numerical simulations section, we evaluate the relationship between effective reproduction number $\left(R_{e}\right)$ to the control measures such as participatory community education programmes $(\xi)$, Clearance of Xcm bacteria in the soil $(\psi)$, Single diseased stem removal $(r)$, and vertical transmission control $(\delta)$. This section also discusses the impact of implementing control measures on disease control.

The parameter values are obtained from related literature and some are assumed in the interval $(0,1)$. The values for the parameters $d, \alpha_{p}, r, \mu_{v}$ and $b_{v}$, are adopted from [31]. The values for the parameters $\beta_{s}, \omega_{1}, \omega_{3}$ and $a$ are from [25]. The value for $b_{p}$ is adopted from [26] and $\theta$ from [12]. Table 3 shows the parameter value per day. In numerical analysis, the MATLAB Runge Kutta $4^{\text {th }}$ order solver was used to verify analytical the results of the model.

Table 3: Values of the model parameters

\begin{tabular}{cccccc}
\hline Parameter & Value/Range & Parameter & Value/Range & Parameter & Value/Range \\
\hline$d$ & 0.0167 & $\omega_{2}$ & 0.4 & $b_{v}$ & 0.02 \\
$\phi$ & 0.89 & $\beta_{s}$ & 0.1429 & $\omega_{1}$ & 0.2 \\
$\alpha_{p}$ & 0.0056 & $K$ & 1000 & $\mu_{v}$ & 0.02 \\
$\theta$ & 0.0286 & $\mu_{h}$ & 0.01 & $\omega_{3}$ & 0.2 \\
$r$ & 0.0105 & $q$ & 0.3 & $\eta$ & 0.0286 \\
$b_{p}$ & 0.01667 & $a$ & 0.2 & $\beta_{a}$ & 0.3 \\
\hline
\end{tabular}

Figure 4 shows that participatory education programmes cause a significant reduction in the effective reproduction number and hence control of the disease. In line with this, [17] and [32] points out that education programmes help farmers to be aware of different modes of BXW disease transmission and proper application of the suggested control measures. 


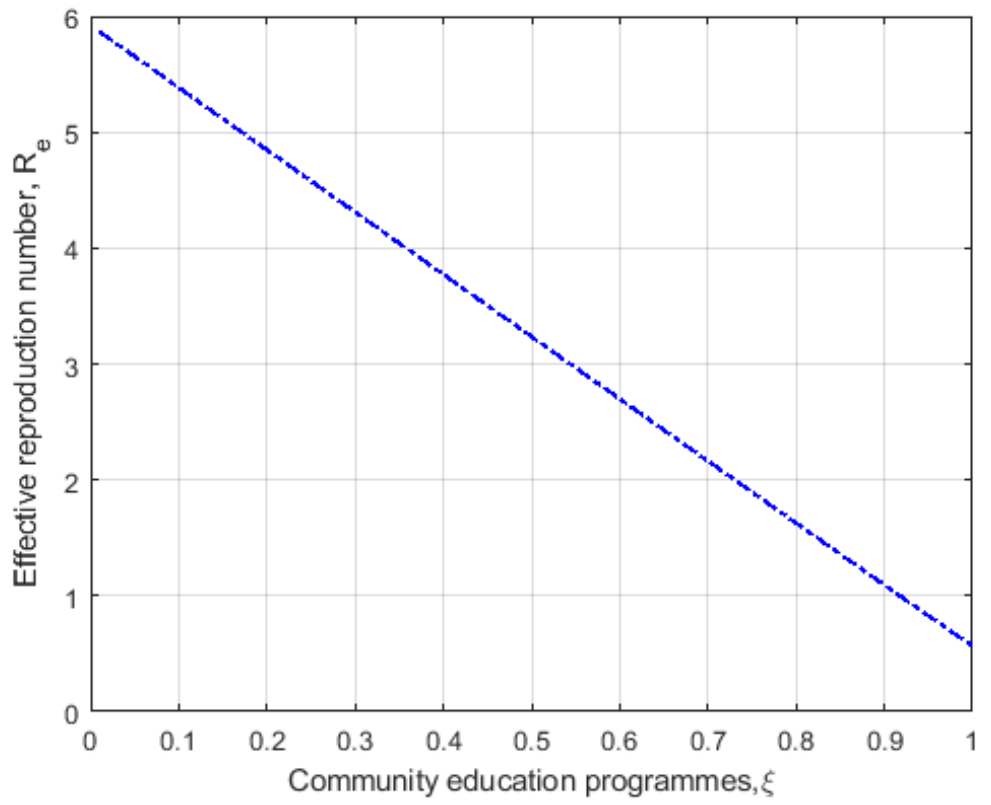

Figure 4: The effect of community participatory education programmes on the $\boldsymbol{R}_{e}$

Figure 5(a) shows that timely removal of symptomatic infected plants from the field is negatively related to the effective reproduction number, while Figure 5(b) indicates that control of vertical transmission is also negatively related to the effective reproduction number. However, removal of symptomatic infected plants is more sensitive compared to the control of mother to child infections $r$ dramatically reduce the effective reproduction number to less than a unit where the disease can be controlled. These results are in agreement with [20] and [33] who established that the single diseased stem removal $(r)$ approach play a great role in avoiding the further spread of the BXW disease. Ocimati et al [18] established that it is possible to find susceptible suckers in the mat where the infected plant rose, this is due to incomplete systemic movement of the Xcm bacteria. This argument has been supported by [33] who found out that proper timely removal of an infected banana plant helps to prevent further spread of the disease to its lateral shoots. Therefore, while finding an effective technology to control vertical transmission, timely removal of an infected banana plants can serve that purpose.

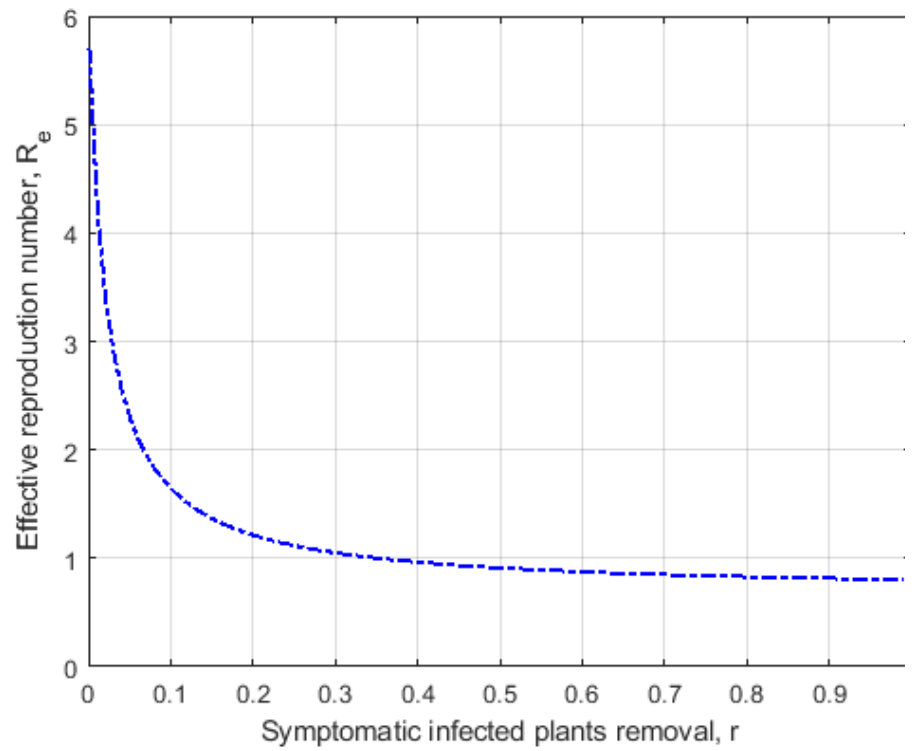

(a) Removal of symptomatic infected banana plants

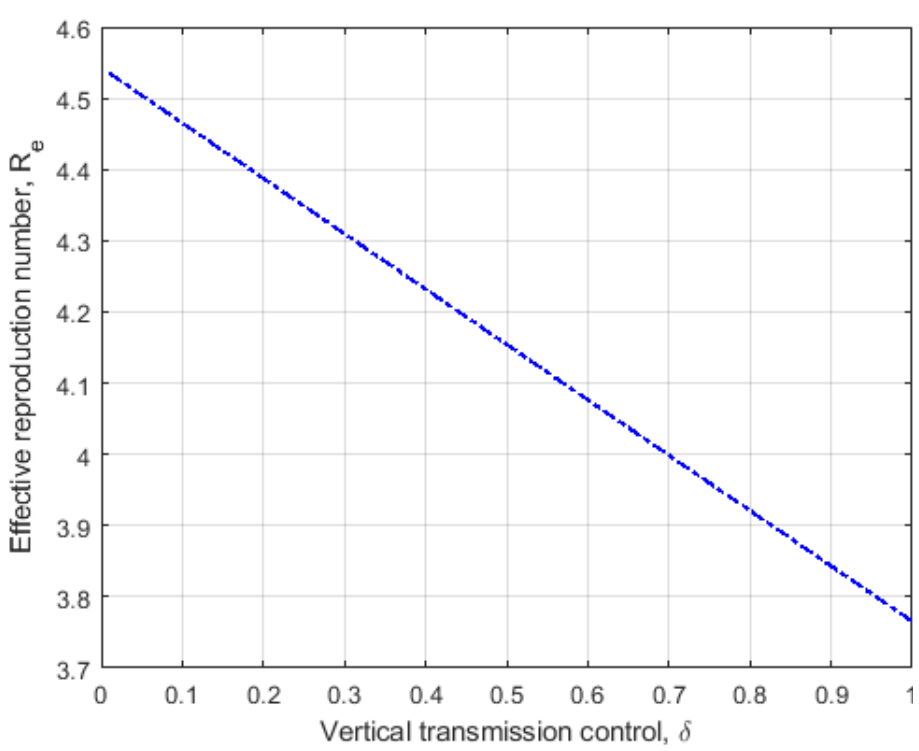

(b) Vertical transmission control

Figure 5: The effect of SDSR and vertical transmission control on the $R_{e}$

Figure 6(a) shows that in the absence of control measures susceptible banana plants decreases dramatically to 0 in 18 months. This is because of the high number of secondary infections. In addition, Figure 6(a) shows that as farmers adopt and practice participatory community education programmes $(\xi)$, clearance of $\mathrm{Xcm}$ bacteria in the soil $(\psi)$, 
single diseased stem removal $(r)$, and vertical transmission control $(\delta)$ the number of susceptible banana plants decreases slowly due to harvesting activities and uprooting for replanting to other fields. On the other hand Figure 6(b) shows that with control measures the rate of susceptible vectors being contaminated with $\mathrm{Xcm}$ bacteria decreases hence decreasing disease transmission through vectors.

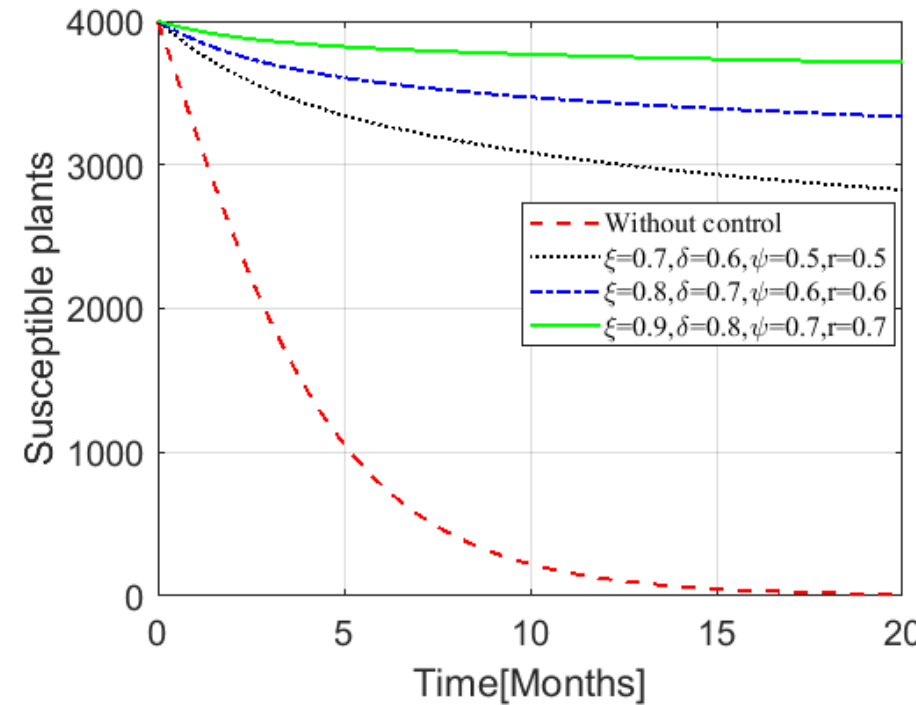

(a) Susceptible banana plants

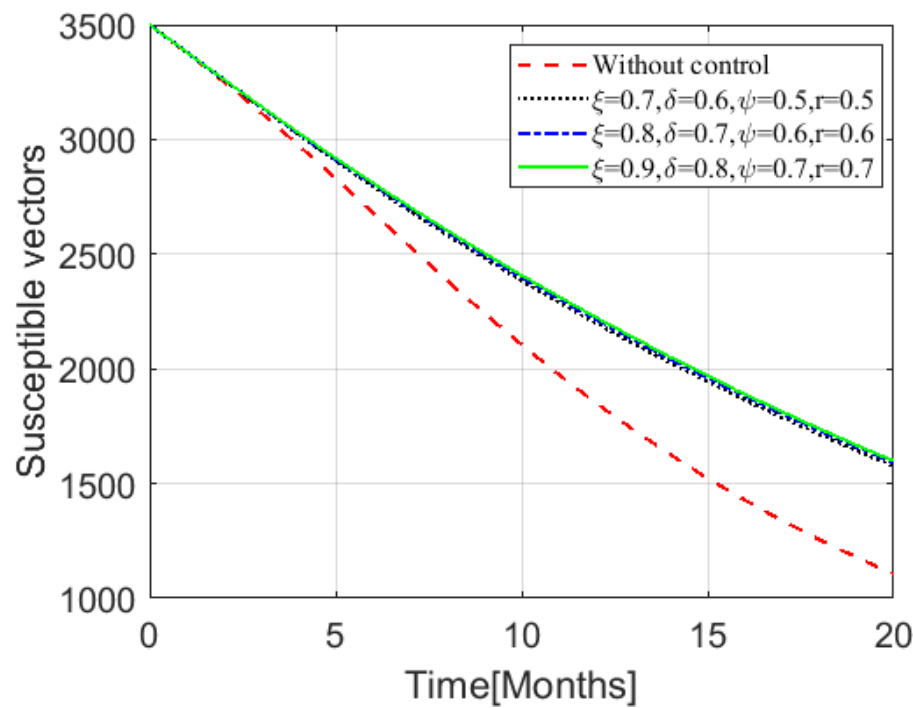

(b) Susceptible vectors

Figure 6: The impact of control measures to the Susceptible banana plants and vectors

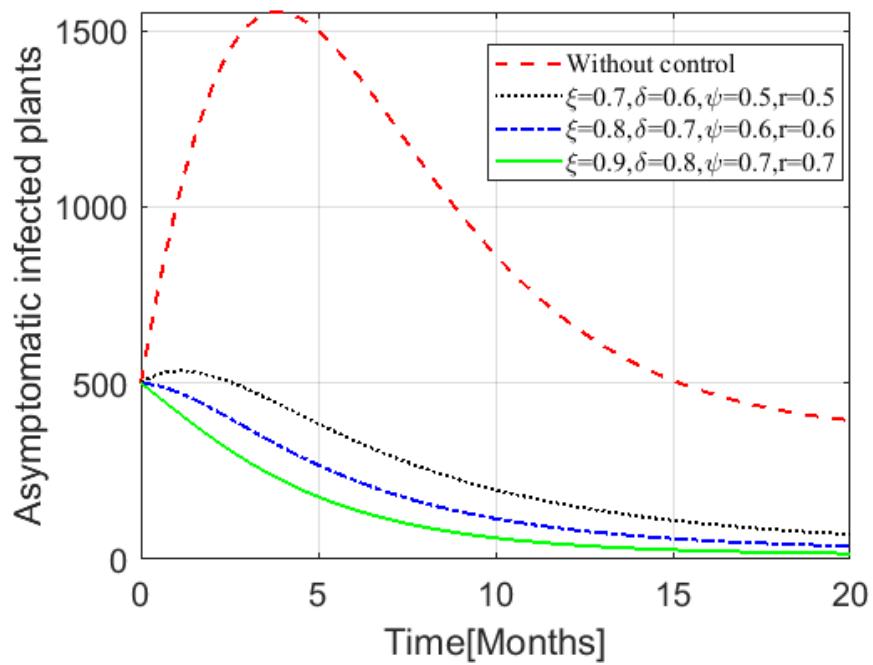

(a) Effect on asymptomatic infected plants

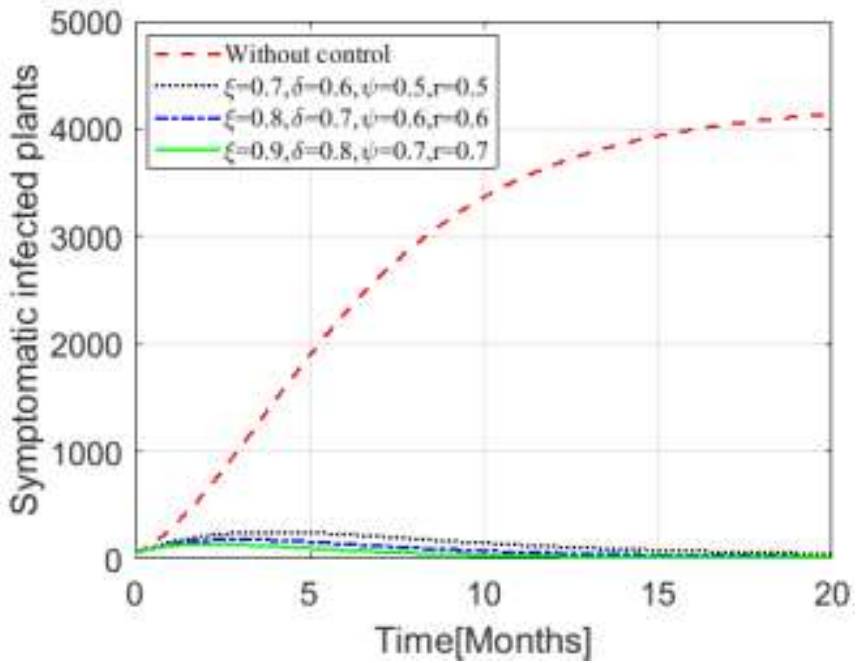

(b) Effect on symptomatic infected plants

Figure 7: The impact of control measures to infected plants

Figure 7(a) shows that without control measures, the number of asymptomatic infected banana plants raise from 500 to 1500 in 5 months. Furthermore, figure 7(a) indicates that as the rate of adopting and practicing the control measures increases, the number of asymptomatic infected plants continuously decreases to zero (0) after 18 months. In addition to that, figure 7(b) shows that when there are no control measures, the number of symptomatic infected banana plants increases from 0 to 4000 after 16 months. This results in a great loss to farmers. Figure 7(b) further shows indicates that even if the disease enters the farm, as the rate of adopting and practicing the participatory community education programmes, clearance of Xcm bacteria in the soil, single diseased stem removal, and vertical transmission control strategies increases, the number of symptomatic infected banana plants remain less than 100 and diminishes to 0 after 10 months. 


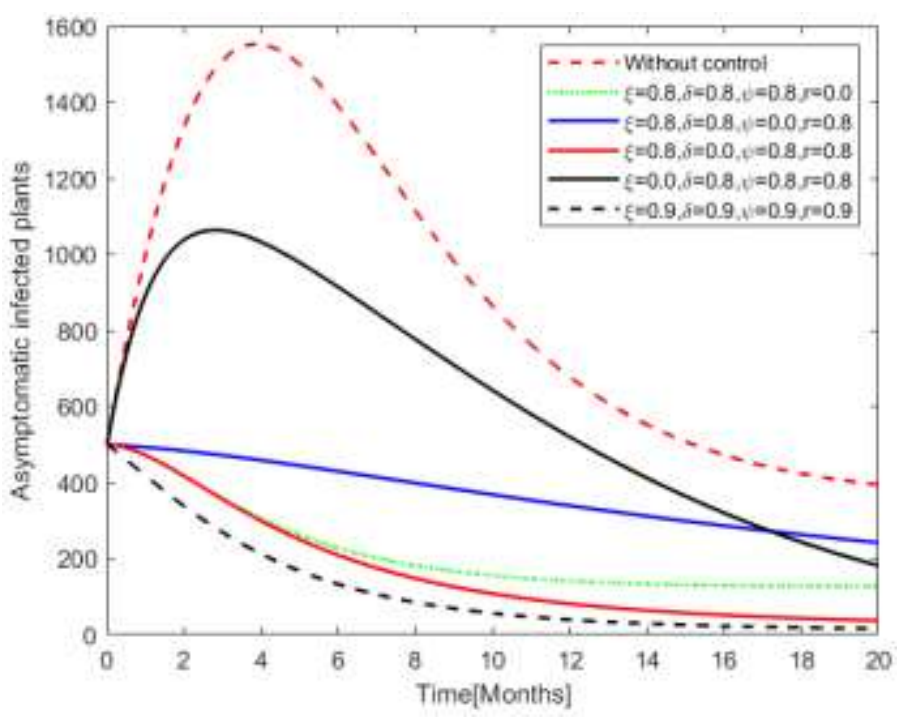

(a) Effect on asymptomatic infected plants

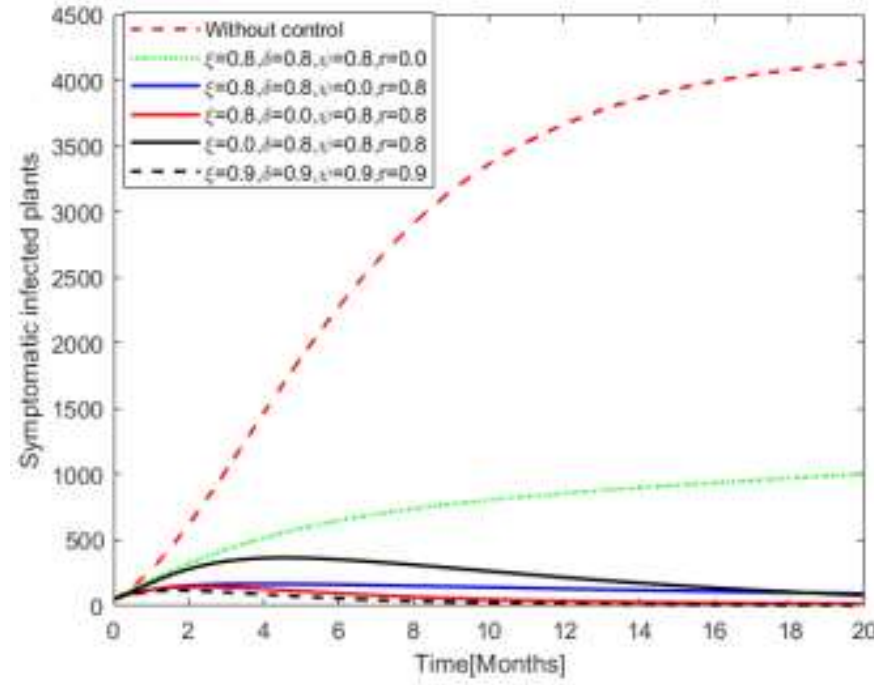

(b) Effect on symptomatic infected plants

Figure 8: The impact of control measures to Asymptomatic and Symptomatic infected banana plants

Figure 8 compares the combination of the control measures so as to determine the effective combination to be adopted. Figure 8(a) shows that when there is no control measures the number of asymptomatic banana plants increases dramatically within the first six months and start decreasing thereafter. It is further observed that when participatory community education is set to 0 the number of asymptomatic remain high. This shows that community education plays a great role in controlling the disease. Furthermore, we observe that when we apply other control measures and set clearance of Xcm bacteria in the soil to 0 the number of asymptomatic decreases slightly. This reveals that clearance of $\mathrm{Xcm}$ bacteria in the soil is important in order to combat the disease. Moreover, Figure 8(a) shows that when all the suggested control measures are adopted up to $90 \%$ the number of asymptomatic decreases fast to 0 within 18 months.

Figure 8(b) shows that when there is no control adopted the number of symptomatic increases dramatically unlike when all the suggested control measures are adopted to $90 \%$. When other controls are applied and SDSR is set to 0 the number of infected plants persists in the farm hence speeding up the rate of infections. this means more emphasis should be on community education and SDSR.

Figure 9(a) shows that without control measures the number of $\mathrm{Xcm}$ bacteria in the soil decreases slowly depending on the natural clearance. But when control measures are correctly adopted and applied including artificial $\mathrm{Xcm}$ bacteria clearance in the soil. The number of Xcm bacteria in the soil decreases rapidly approaching 0 in 8 months. On the other hand, when no control is applied in the field, symptomatic infected banana plants increases up to 4000 after 20 months while with control measures symptomatic infected banana plants increases in a very small number from 2 to 6 months and decreases to zero (0) in 15 months. Figure 9(b) shows that applying other control measures and ignoring clearance of $\mathrm{Xcm}$ bacteria in the soil leads to persistence of the disease in the soil and hence persistence of the BXW disease in the farm. Therefore in order to best control the disease and avoid reoccurring, clearance of $\mathrm{Xcm}$ bacteria in the soil should be given more emphasis. 


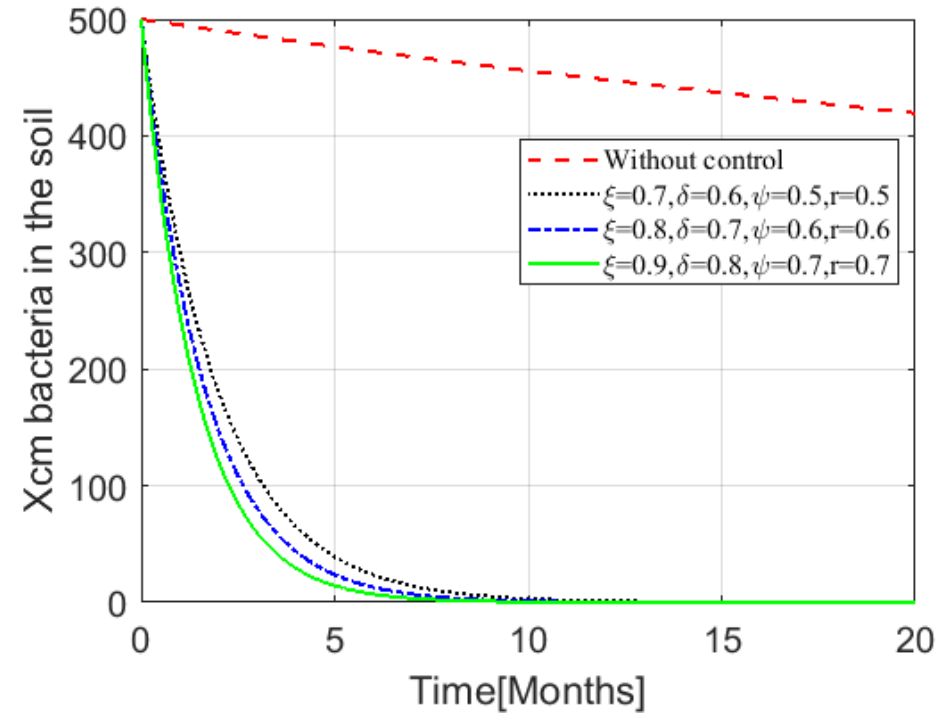

(a) Effect on

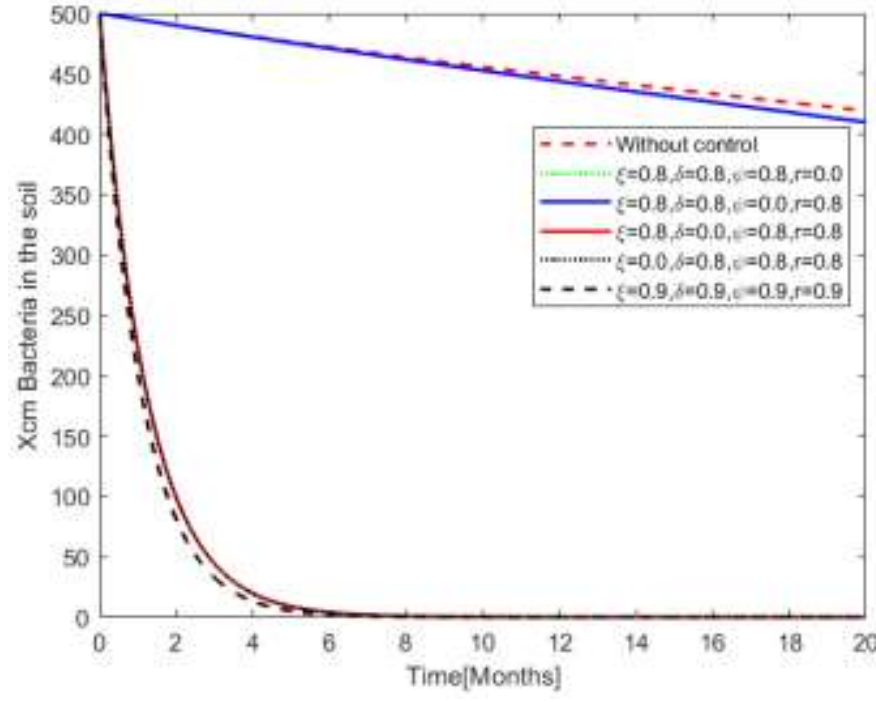

(b) Effect on

Figure 9: The impact of control measures to the number of $X \mathrm{~cm}$ bacteria in the soil

\section{CONCLUSION AND RECOMMENDATIONS}

In this paper, a deterministic mathematical model for Banana Xanthomonas wilt (BXW) disease is formulated and analysed. The aim was to get an understanding of the transmission dynamics of BXW disease when some control strategies are considered. The control strategies included in this mathematical model include participatory community education programmes; clearance of Xcm bacteria in the soil; single diseased stem removal and vertical transmission control measures.

The basic model was formulated and analyzed. The results showed that when participatory community education programmes, clearance of $\mathrm{Xcm}$ bacteria in the soil, single diseased stem removal and vertical transmission control are applied they dramatically reduce further spread of the BXW disease. Therefore, we recommend that participatory community education programmes, clearance of $\mathrm{Xcm}$ bacteria in the soil, single diseased stem removal, and vertical transmission control strategies be applied in line with the current control strategies such as timely removal of the male bud using a forked stick, sterilization of farming tools, and planting of healthy suckers to avoid further introduction new infections in the field.

\section{ACKNOWLEDGEMENTS}

The authors would like to thank the African Centre for Research, Agricultural advancement, Teaching Excellence and Sustainability (CREATES) for funding this research and all the people who in one way or another contributed to the completion of this article.

\section{REFERENCES}

[1] FAO, "FAO STATISTICS.” 2018.

[2] L. Tripathi, M. Mwangi, S. Abele, V. Aritua, W. K. Tushemereirwe, and R. Bandyopadhyay, "Xanthomonas wilt: a threat to banana production in East and Central Africa," Plant Dis., vol. 93, no. 5, pp. 440-451, 2009.

[3] J. Nakakawa, J. Y. T. Mugisha, W. S. Michael, W. Tinzaara, and E. Karamura, "Banana Xanthomonas Wilt Infection: The Role of Debudding and Roguing as Control Options within a Mixed Cultivar Plantation," Int. J. Math. Math. Sci., vol. 2017, pp. 1-13, 2017.

[4] F. Ssekiwoko, H. K. Taligoola, and W. K. Tushemereirwe, "Xanthomonas campestris pv musacearum host range in Uganda," African Crop Sci. J., vol. 14, no. 2, pp. 111-120, 2007.

[5] H. Buregyeya, J. Kubiriba, G. Tusiime, R. Kityo, and F. Ssekiwoko, "Role of Birds \& Bats in Long Distance Transmission of Banana Bacterial Wilt in Uganda," 2014.

[6] A. Rutikanga, G. Tusiime, G. Night, W. Ocimati, and G. Blomme, "Variation in nectar volume and sugar content in male flowers of Musa cultivars grown in Rwanda and their non-effect on the numbers of visiting key diurnal insect vectors of 
banana Xanthomonas wilt," 2016.

[7] G. Blomme et al., "Fine-tuning banana Xanthomonas wilt control options over the past decade in East and Central Africa," Eur. J. plant Pathol., vol. 139, no. 2, pp. 271-287, 2014.

[8] J. M. Mwebaze, G. Tusiime, W. K. Teshemereirwe, and J. Kubiriba, "The survival of Xanthomonas campestris pv. musacearum in soil and plant debris," African Crop Sci. J., vol. 14, no. 2, 2006.

[9] I. Hashim, "Banana xanthomonas wilt: incidence, transmission, pathogen characterization and management options in Kagera, Mwanza and Mara regions,” Sokoine University of Agriculture, 2013.

[10] M. Shehabu, T. Addis, S. Mekonen, D. De Waele, and G. Blomme, "Nematode infection predisposes banana to soil-borne Xanthomonas campestris pv. musacearum transmission," Tree For. Sci. Biotechnol, vol. 4, pp. 63-64, 2010.

[11] C. Sivirihauma, W. Ocimati, L. Vutseme, J. Ntamwira, L. Bahati, and G. Blomme, "Symptomless banana suckers sourced from Xanthomonas wilt infected fields are a viable alternative for seed within infected banana-based landscapes lacking access to clean planting materials," 2017.

[12] W. Ocimati, F. Ssekiwoko, E. Karamura, W. Tinzaara, S. Eden-Green, and G. Blomme, "Systemicity of X anthomonas campestris pv. musacearum and time to disease expression after inflorescence infection in $\mathrm{E}$ ast A frican highland and $\mathrm{P}$ isang A wak bananas in U ganda," Plant Pathol., vol. 62, no. 4, pp. 777-785, 2013.

[13] J. Kubiriba and W. K. Tushemereirwe, “Approaches for the control of banana Xanthomonas wilt in East and Central Africa,” African J. Plant Sci., vol. 8, pp. 398-404, 2014.

[14] V. Nakato, G. Mahuku, and T. Coutinho, "Xanthomonas campestris pv. musacearum: a major constraint to banana, plantain and enset production in central and east Africa over the past decade," Mol. Plant Pathol., vol. 19, no. 3, pp. 525$536,2018$.

[15] M. Maina, T. William, V. Ndungo, N. Flora, R. Philip, and B. Ranajit, "Comparative study of banana Xanthomonas wilt spread in mid and high altitudes of the Great Lakes region of Africa," 2006.

[16] H. Buregyeya, "Evaluation of the contribution of birds, bats and farm tools in the long distance transmission of banana bacterial wilt," Masters' thesis, Makerere University, Kampala Uganda, 2010.

[17] J. Kubiriba, E. B. Karamura, W. Jogo, W. K. Tushemereirwe, and W. Tinzaara, "Community mobilization: a key to effective control of banana Xanthomonas wilt," 2012.

[18] W. Ocimati, G. V Nakato, K. M. Fiaboe, F. Beed, and G. Blomme, "Incomplete systemic movement of X anthomonas campestris pv. musacearum and the occurrence of latent infections in xanthomonas wilt-infected banana mats," Plant Pathol., vol. 64, no. 1, pp. 81-90, 2015.

[19] G. Blomme et al., "A control package revolving around the removal of single diseased banana stems is effective for the restoration of Xanthomonas wilt infected fields," Eur. J. plant Pathol., vol. 149, no. 2, pp. 385-400, 2017.

[20] J. Ntamwira, G. Blomme, L. Bahati, and W. Ocimati, "Effect of timing of diseased plant cutting, altitude and banana cultivar on efficacy of singly removing Xanthomonas wilt infected banana plants," Eur. J. Plant Pathol., pp. 1-13, 2019.

[21] F. Uwamahoro, A. Berlin, H. Bylund, C. Bucagu, and J. Yuen, "Management strategies for banana Xanthomonas wilt in Rwanda include mixing indigenous and improved cultivars," Agron. Sustain. Dev., vol. 39, no. 2, p. $22,2019$.

[22] S. Ma and Y. Xia, Mathematical understanding of infectious disease dynamics, vol. 16. World Scientific, 2009.

[23] C. I. Siettos and L. Russo, "Mathematical modeling of infectious disease dynamics," Virulence, vol. 4, no. 4, pp. 295-306, 2013.

[24] K. E. Horub and T. Julius, "A Mathematical Model for the Vector Transmission and Control of Banana Xanthomonas Wilt," J. Math. Res., vol. 9, no. 4, pp. 101-113, 2017.

[25] B. Nannyonga, L. S. Luboobi, P. Tushemerirwe, and M. Jabłońska-Sabuka, "Using contaminated tools fuels outbreaks of Banana Xanthomonas wilt: An optimal control study within plantations using Runge-Kutta fourth-order algorithms," Int. J. Biomath., vol. 08, no. 05, p. 1550065, 2015.

[26] J. Nakakawa, J. Y. T. Mugisha, W. S. Michael, and E. Karamura, "A Mathematical Model for the Dynamics of Banana Xanthomonas Wilt With Vertical Transmission and Inflorescence Infection,” J. Biol. Syst., vol. 24, no. 01, pp. 147-165, 2016.

[27] E. H. Kweyunga, J. Tumwiine, and E. Karamura, "Modeling the dynamics of banana Xanthomonas wilt transmission incorporating infectious force in both asymptomatic and symptomatic stages," 2018. 
[28] J. J. Mapinda, G. G. Mwanga, and V. Masanja, "Modelling the transmission dynamics of banana xanthomonas wilt disease with contaminated soil," J. Math. Informatics, vol. 17, pp. 113-129, 2019.

[29] P. den Driessche and J. Watmough, "Reproduction numbers and sub-threshold endemic equilibria for compartmental models of disease transmission," Math. Biosci., vol. 180, no. 1-2, pp. 29-48, 2002.

[30] O. Diekmann, J. A. P. Heesterbeek, and M. G. Roberts, "The construction of next-generation matrices for compartmental epidemic models," J. R. Soc. Interface, vol. 7, no. 47, pp. 873-885, 2009.

[31] E. H. Kweyunga, "Mathematical models for the transmission and control of banana bacterial wilt epidemic," Mbarara University of Science and Technology, 2011.

[32] D. Ochola, W. Jogo, W. Tinzaara, M. Odongo, M. Onyango, and E. Karamura, "Farmer field school and banana xanthomonas wilt management: A study of banana farmers in four villages in Siaya County, Kenya," J. Agric. Ext. Rural Dev., vol. 7, no. 12, pp. 311-321, 2015.

[33] G. Blomme et al., "A control package revolving around the removal of single diseased banana stems is effective for the restoration of Xanthomonas wilt infected fields," Eur. J. Plant Pathol., vol. 149, no. 2, pp. 385-400, 2017. 